\title{
Circulating regulatory $T$ cell subsets predict overall survival of patients with unresectable pancreatic cancer
}

\author{
CHEN LIU ${ }^{1-3^{*}}$, HE CHENG $^{1-3^{*}}$, GUOPEI LUO ${ }^{1-3^{*}}, \mathrm{YU} \mathrm{LU}^{1-3}$, \\ KAIZHOU JIN ${ }^{1-3}$, MENG GUO ${ }^{1-3}$, QUANXING NI ${ }^{1-3}$ and XIANJUN YU ${ }^{1-3}$ \\ ${ }^{1}$ Department of Pancreatic Surgery, Fudan University Shanghai Cancer Center, Shanghai 200032; \\ ${ }^{2}$ Department of Oncology, Shanghai Medical College, Fudan University, Shanghai 200032; \\ ${ }^{3}$ Pancreatic Cancer Institute, Fudan University, Shanghai 200032, P.R. China
}

Received February 9, 2017; Accepted May 29, 2017

DOI: $10.3892 /$ ijo.2017.4032

\begin{abstract}
Most patients with pancreatic ductal adenocarcinoma (PDAC) have unresectable cancers with a dismal prognosis, in which cohort chemotherapy is the primary treatment. $\mathrm{T}$ cell immune adaption is critical for tumor immune escape and prognosis of this disease. The present study aimed to determine the correlation between peripheral $\mathrm{T}$ cell subset distribution in patients with unresectable PDAC and their response to chemotherapy. Two hundred and twelve patients with unresectable PDAC were included whose blood samples were collected for analysis of $\mathrm{T}$ cell subsets, including $\mathrm{CD}^{+}$, $\mathrm{CD} 4^{+}, \mathrm{CD}^{+}, \mathrm{CD} 8^{+} \mathrm{CD} 28^{+}$and $\mathrm{CD} 4^{+} \mathrm{CD} 25^{+} \mathrm{CD} 127 \mathrm{~T}$ cells by flow cytometry before and after gemcitabine-based chemotherapy. Enzyme-linked immunosorbent assay was used to detect the expression levels of tumor growth factor (TGF)- $\beta 1$, interleukin (IL)-6 and IL-17A in the patients before and after chemotherapy. Univariate and multivariate analyses found that an initial CD4/CD8 ratio or T regulatory (Treg) cell level before any treatment was associated with the prognosis of unresectable PDAC. After two cycles of chemotherapy, there was no significant change in percentages of $\mathrm{T}$ cell subsets, except elevation to a higher level of $\mathrm{CD}^{+} \mathrm{T}$ cells. Decreased Tregs or CD4/CD8 ratio after two cycles of chemotherapy predicts a longer overall survival (OS). Levels of Tregs in stable disease (SD) and partial remission (PR) cases significantly decreased after chemotherapy, but increased in progressive disease (PD) patients. There was no correlation between Tregs and the expression level of either TGF- $\beta 1$ or IL- 6 . IL-17A expression was elevated in Treg-decreased patients, whereas IL-17A was reduced in Treg-increased patients after chemotherapy. The circulating signature of $\mathrm{T}$ cell subsets can predict
\end{abstract}

Correspondence to: Professor Xianjun Yu, Department of Pancreatic Surgery, Shanghai Cancer Center, Fudan University, No. 270 Dong An Road, Shanghai 200032, P.R. China

E-mail: yuxianjun@fudanpci.org

*Contributed equally

Key words: pancreatic cancer, chemotherapy, $\mathrm{T}$ cell subset, regulatory $\mathrm{T}$ cell, tumor microenvironment
OS and chemotherapeutic response in patients with unresectable PDAC, and may be attributable to the plasticity of $\mathrm{T}$ cell subsets.

\section{Introduction}

Even with the rapid development of surgical techniques and a broader understanding of oncology over the past few decades, pancreatic ductal adenocarcinoma (PDAC) remains at a 5-year survival rate of 5-6\% (1,2). Only approximately $15-20 \%$ of patients with PDAC are suitable for surgical resection, which is the best possible treatment for good oncologic outcome $(1,2)$. For most pancreatic cancers that are locally advanced or metastatic, the National Comprehensive Cancer Network (NCCN) recommends chemotherapy (1-4). However, only a limited subgroup of these patients will really benefit from chemotherapy; instead, patients often have severe adverse events, and even a more progressive disease (1-4). Therefore, it is necessary to select the patients with unresectable PDAC that could have a better prognosis or benefit from chemotherapy. Different tumor biological characteristics may contribute to better outcomes in this subgroup of patients. Unfortunately, there is still a lack of a simple and effective marker to identify these patients.

Generally, PDAC, especially advanced cases, is accompanied by obstruction of the pancreatic duct and varying degrees of chronic pancreatitis, which contribute to a unique tumor microenvironment comprising a specific network of multiple immune and inflammatory factors $(5,6)$. It was reported that a dynamic imbalance involving $\mathrm{CD}^{+} \mathrm{T}$ cells and $\mathrm{CD}^{+} \mathrm{T}$ cells contributed to tumor immune escape and failure of immune surveillance during pancreatic tumorigenesis (5-7). T regulatory (Treg) cells, one of the main subsets of $\mathrm{CD} 4^{+} \mathrm{T}$ helper cells, were reported to be recruited by the pancreatic tumor microenvironment from a pre-invasive stage to invasive and metastatic PDAC and played a crucial role in immunosuppression (6,7). Previously, we found that peripheral Treg levels were significantly increased in patients with PDAC compared with that of healthy donors and patients with benign pancreatic disease; furthermore, for patients with PDAC who underwent a radical resection, the percentage of peripheral Tregs was regarded as an independent prognostic factor (8). Although it has been widely confirmed that infiltrating immune cells 
in tumor tissue have prognostic values (5-7), whether the systemic quantifiable immune parameters also have prognostic value is an interesting question. The authors consider that the data of circulating immune parameters are more widely available than the data of infiltrating immune cells. Thus, if the circulating immune parameters have prognostic value, the makers would be more convenient and accessible to monitor tumor progression. Therefore, the present study focused on circulatory immune cells to explore prognostic markers, based on retrospective analysis. In addition, tissue samples obtained through EUS-FNA in unresectable pancreatic cancer patiens are rare and limited and often insufficient for tumor microenvironment analysis. In the present study, although the results are not direct evidence, consideration should be given that PDCA caused the abnormal distribution of peripheral $\mathrm{T}$ lymphocyte subsets.

Chemotherapy is a primary treatment for advanced or metastatic PDAC; however, a new perspective has emerged that the cytotoxic effects of chemotherapy not only destroys tumor cells, but also impairs immune cells that subsequently damage the antitumor response and even promote tumor growth and metastasis (9-11). In this study, we aimed to observe the alteration and distribution of peripheral $\mathrm{T}$ cell subsets in patients with unresectable PDAC, evaluate the effect of chemotherapy on T cell-related immune system, and discover some effective factors that could predict systemic chemotherapy response in patients with unresectable PDAC.

\section{Materials and methods}

Patients. The present study included all patients with unresectable pancreatic cancer who received treatment at our center during October 2010 to December 2015, including locally advanced and metastatic cases according to the American Joint Committee on Cancer (AJCC, 7th edition). These patients were diagnosed on the basis of pathology using biopsy samples obtained by endoscopic ultrasound-guided fineneedle aspiration (EUS-FNA). Most of the patients (81.1\%) underwent gemcitabine (gemcitabine at $1000 \mathrm{mg} / \mathrm{m}^{2}$ over $30 \mathrm{~min}$, weekly for 3 weeks every 28 days) or gemcitabinebased combination therapy according to NCCN Guidelines. This study was approved by the Clinical Research Ethics Committee of Shanghai Cancer Center of Fudan University, and written informed consent was provided by each patient. All clinicopathological data were retrieved from electronic records. Computed tomography (CT) was used to evaluate the treatment response every 2 months according to the guidelines of Response Evaluation Criteria in Solid Tumors (RECIST) 1.0. The primary endpoint of this study was overall survival (OS), which was measured by comparing the date of diagnosis to the date of death, and the last follow-up date was June 2016 with three patients still alive. The median survival of this cohort of patients is 7 months, with 5.8 months in stage IV patients and 9.2 months in locally advanced patients.

Blood sample collection and flow cytometry. Venous blood samples were obtained in heparinized tubes at admission before or after two-cycle chemotherapy, and the samples were immediately analyzed by flow cytometry. Monoclonal antibodies (eBiosciences) used to identify different $\mathrm{T}$ lymphocyte
Table I. Clinicopathological parameters of patients with unresectable pancreatic cancer $(\mathrm{N}=212)$.

\begin{tabular}{|c|c|}
\hline Parameters & $\mathrm{N}(\%)$ \\
\hline \multicolumn{2}{|c|}{ Age (years) (median, 61; range, 33-82) } \\
\hline$<60$ & $90(42.5)$ \\
\hline$\geq 60$ & $122(57.5)$ \\
\hline \multicolumn{2}{|l|}{ Gender } \\
\hline Male & $133(62.7)$ \\
\hline Female & $79(37.3)$ \\
\hline \multicolumn{2}{|l|}{ PS } \\
\hline $90-100$ & $78(36.8)$ \\
\hline $70-80$ & $134(63.2)$ \\
\hline \multicolumn{2}{|l|}{ Tumor location } \\
\hline Body and tail & $94(44.3)$ \\
\hline Head & $118(55.7)$ \\
\hline \multicolumn{2}{|l|}{ TNM stage } \\
\hline III & $76(35.8)$ \\
\hline IV & $136(64.2)$ \\
\hline \multicolumn{2}{|c|}{$\begin{array}{l}\text { CA19-9 levels }(\mathrm{U} / \mathrm{ml}) \\
(\text { median, 301.3; range, 0.68->1000 U/ml) }\end{array}$} \\
\hline$<301.3$ & $106(50)$ \\
\hline$\geq 301.3$ & $106(50)$ \\
\hline \multicolumn{2}{|c|}{ CA125 levels (U/ml) } \\
\hline$<35$ & $101(47.6)$ \\
\hline$\geq 35$ & $111(52.4)$ \\
\hline \multicolumn{2}{|l|}{ Chemotherapy } \\
\hline Yes & $172(81.1)$ \\
\hline No & $40(18.9)$ \\
\hline \multicolumn{2}{|l|}{ Survival status } \\
\hline Alive & $3(1.4)$ \\
\hline Dead & $209(98.6)$ \\
\hline
\end{tabular}

PS, performance status.

subsets were as follows: anti-CD3 FITC, anti-CD4 PE-Cy ${ }^{\mathrm{TM}} 7$, and anti-CD8 APC-Cy7. Anti-CD8 FITC and anti-CD28 PE were used to detect $\mathrm{CD} 8^{+} \mathrm{CD} 28^{+} \mathrm{T}$ cells. Anti-CD4 FITC, anti-CD25 PE and anti-CD127 APC were applied to identify Tregs. Statistical analyses involved at least 10,000 events gated on the population of interest. Detailed steps for the detection of different $\mathrm{T}$ lymphocyte subsets in blood samples are previously described (8).

Enzyme-linked immunosorbent assay (ELISA). Serum samples from patients were prospectively collected after centrifugation at $3,000 \mathrm{rpm}$ for $10 \mathrm{~min}$ at $4^{\circ} \mathrm{C}$. Then, the supernatants were divided and cryopreserved at $-80^{\circ} \mathrm{C}$. The following parameters were measured: IL-17A was determined using the human IL-17A ELISA kit (eBioscience); IL-6 was determined using the human IL-6 ELISA kit (eBioscience); and TGF- $\beta 1$ was determined using the human TGF- $\beta 1$ ELISA kit (eBioscience). The measurements were performed according to the manufac- 
Table II. Univariate and multivariate analyses of clinicopathological parameters for the prediction of overall survival in patients with unresectable pancreatic cancer $(\mathrm{N}=212)$.

\begin{tabular}{|c|c|c|c|c|}
\hline \multirow[b]{2}{*}{ Parameters } & \multicolumn{2}{|c|}{ Univariate analyses } & \multicolumn{2}{|c|}{ Multivariate analyses } \\
\hline & P-value & HR $(95 \%$ CI) & P-value & HR (95\% CI) \\
\hline Age (years) & 0.844 & & 0.899 & \\
\hline$<60$ vs. $\geq 60$ & & - & & - \\
\hline Gender & 0.405 & & 0.229 & \\
\hline Male vs. female & & - & & - \\
\hline $\begin{array}{l}\text { PS } \\
\text { (90-100) vs. (70-80) }\end{array}$ & 0.003 & $\begin{array}{c}0.645 \\
(0.482-0.862)\end{array}$ & 0.041 & $\begin{array}{c}0.722 \\
(0.544-0.987)\end{array}$ \\
\hline $\begin{array}{l}\text { TNM stage } \\
\text { III vs. IV }\end{array}$ & 0.001 & $\begin{array}{c}0.603 \\
(0.453-0.804)\end{array}$ & 0.002 & $\begin{array}{c}0.61 \\
(0.448-0.83)\end{array}$ \\
\hline $\begin{array}{l}\text { CA19-9 level }(\mathrm{U} / \mathrm{ml}) \\
<301.3 \text { vs. } \geq 301.3\end{array}$ & 0.018 & $\begin{array}{c}0.718 \\
(0.545-0.945)\end{array}$ & 0.01 & $\begin{array}{c}0.69 \\
(0.52-0.916)\end{array}$ \\
\hline $\begin{array}{l}\text { CA125 level }(\mathrm{U} / \mathrm{ml}) \\
<35 \text { vs. } \geq 35\end{array}$ & $<0.001$ & $\begin{array}{c}0.598 \\
(0.453-0.789)\end{array}$ & 0.082 & - \\
\hline $\begin{array}{l}\text { Chemotherapy } \\
\text { Yes vs. no }\end{array}$ & $<0.001$ & $\begin{array}{c}0.429 \\
(0.299-0.614)\end{array}$ & $<0.001$ & $\begin{array}{c}0.428 \\
(0.292-0.627)\end{array}$ \\
\hline $\begin{array}{l}\mathrm{CD}^{+} \mathrm{T} \text { cells } \\
\text { High vs. low }(132 / 80)\end{array}$ & 0.144 & - & & \\
\hline $\begin{array}{l}\mathrm{CD}^{+} \mathrm{T} \text { cells } \\
\text { High vs. low }(124 / 88)\end{array}$ & 0.18 & - & & \\
\hline $\begin{array}{l}\text { CD8 }{ }^{+} \mathrm{T} \text { cells } \\
\text { High vs. low }(114 / 98)\end{array}$ & 0.527 & - & & \\
\hline $\begin{array}{l}\mathrm{CD}^{+}{ }^{+} \mathrm{CD} 28^{+} \mathrm{T} \text { cells } \\
\text { High vs. low }(181 / 28)\end{array}$ & 0.126 & & & \\
\hline $\begin{array}{l}\text { Tregs }\left(\mathrm{CD} 4^{+} \mathrm{CD} 25^{+} \mathrm{CD} 127^{-}\right) \\
\text {High vs. low }(41 / 171)\end{array}$ & 0.004 & $\begin{array}{c}1.656 \\
(1.169-2.347)\end{array}$ & 0.015 & $\begin{array}{c}1.567 \\
(1.09-2.257)\end{array}$ \\
\hline $\begin{array}{l}\text { CD4/CD8 ratio } \\
\text { High vs. low }(83 / 129)\end{array}$ & 0.025 & $\begin{array}{c}1.379 \\
(1.043-1.828)\end{array}$ & 0.032 & $\begin{array}{c}1.374 \\
(1.021-1.835)\end{array}$ \\
\hline
\end{tabular}

HR, hazard ratio; $95 \% \mathrm{CI}, 95 \%$ confidence interval.

turer's protocol. The results are expressed as $\mathrm{pg} / \mathrm{ml}$. In this study, 100 pairs (before and after two-cycle chemotherapy) of cryopreserved serum samples were available for analysis.

Statistical analysis. The SPSS version 16.0 statistical software package and the Graphpad Prism version 6.0 (GraphPad, Inc., San Diego, CA, USA) were used for statistical analysis. Overall survival curves were compared using the log-rank test. Univariate and multivariate analyses were used to examine potentially independent prognostic factors. Student's t-test was used for continuous variables between two groups. Differences with a P-value (two-sided) of $<0.05$ were considered to be statistically significant.

\section{Results}

The patient clinicopathological characteristics. Two hundred and twelve patients with unresectable PDAC were included in this study, including 76 locally advanced and 136 metastatic cases, with a median age of 61 years (range, 33-82 years). Among this cohort of patients, 172 (81.1\%) patients underwent gemcitabine-based chemotherapy, and another 40 (18.9\%) patients received only palliative or best supportive care. We detected peripheral $\mathrm{T}$ cell subsets in all 212 patients before any treatment and monitored the alteration in $\mathrm{T}$ cell subsets in 100 patients who underwent two cycles of chemotherapy. The patient characteristics are summarized in Table I.

The status of peripheral $T$ cell subsets predicts overall survival in patients with unresectable pancreatic cancer before treatment. In univariate and multivariate analyses of clinicopathological parameters for pancreatic cancer, we found that the serum level of CA19-9, performance status (PS), TNM stage, and chemotherapy or no chemotherapy were independent prognostic factors for unresectable PDAC. For circulating $\mathrm{T}$ cell subsets, an initial CD4/CD8 ratio or Treg level before any treatment was associated with the prognosis of locally advanced and metastatic disease (Table II and Fig. 1). 

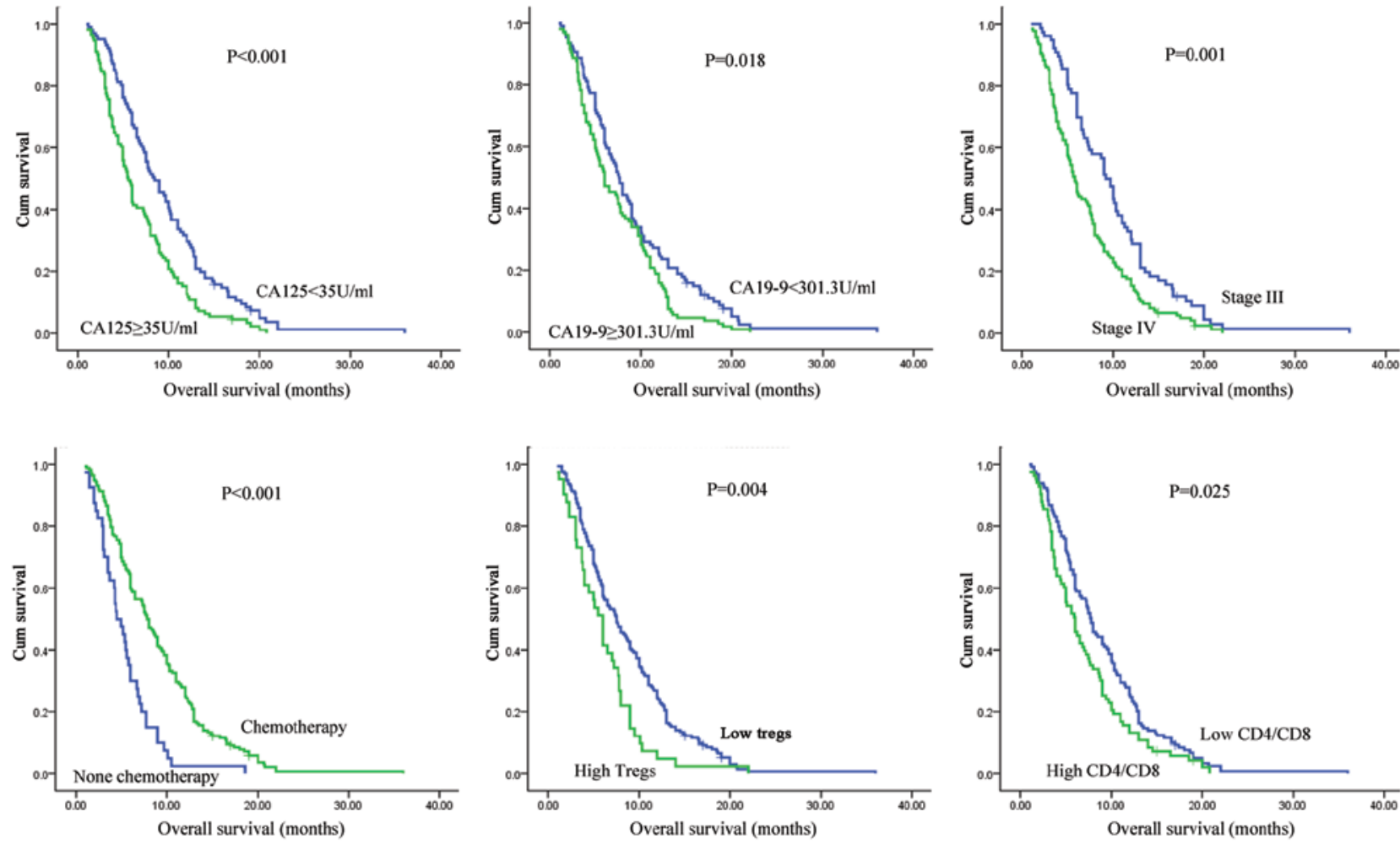

Figure 1. Kaplan-Meier analyses of the overall survival difference in patients with unresectable pancreatic cancer. Groups were compared by univariate analysis. The cut-off point for $\mathrm{T}$ cell subsets was determined using ROC curves.
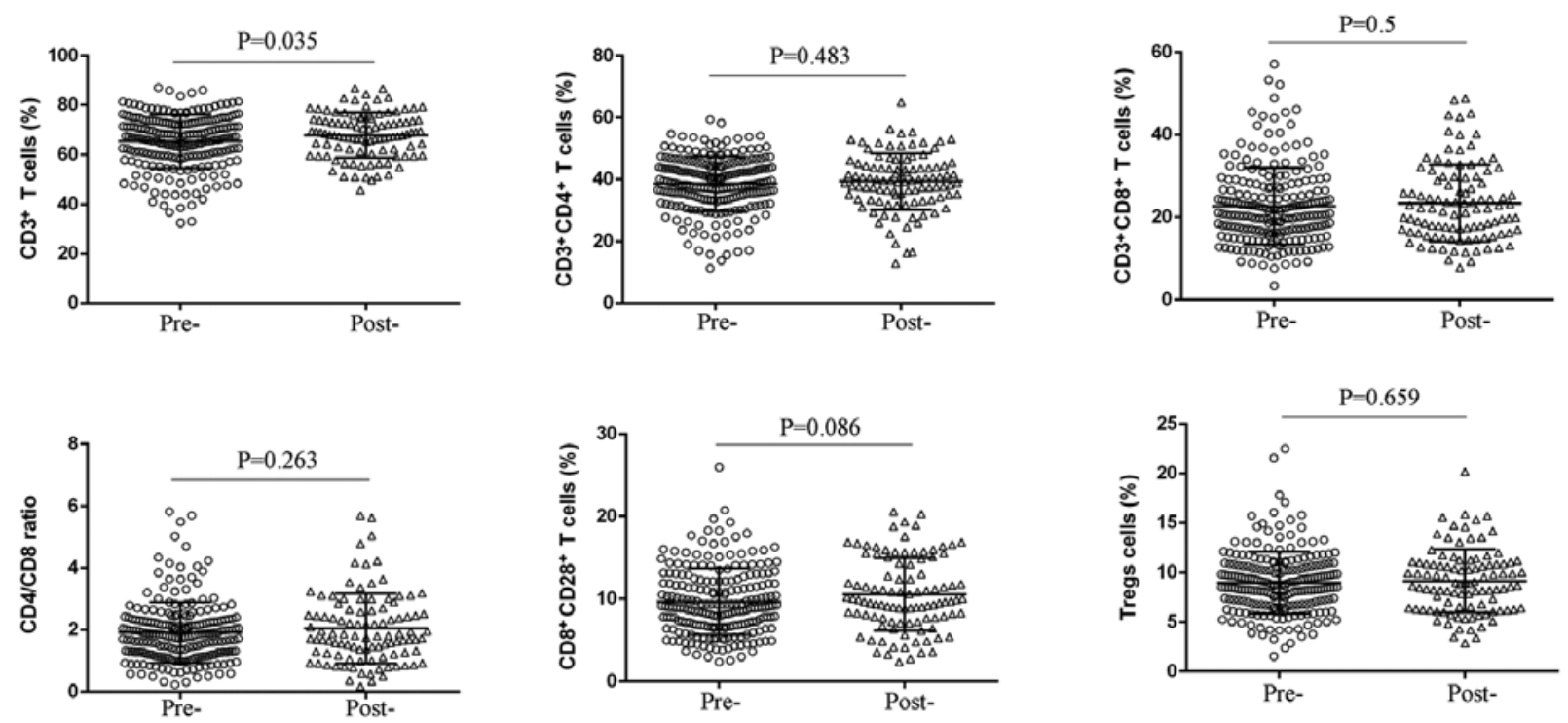

Figure 2. Distribution of peripheral T cell subsets in patients with unresectable pancreatic cancer before and after chemotherapy. Pre, pre-chemotherapy; Post, post-chemotherapy.

Alteration in peripheral $T$ cell subsets predicts chemotherapeutic response in patients with unresectable pancreatic cancer. After two cycles of chemotherapy, we detected the peripheral $\mathrm{T}$ cell subsets to observe the effect of chemotherapy on $\mathrm{T}$ cell immune response, and found that there was no significant change in percentages of $\mathrm{CD} 3^{+} \mathrm{CD} 4^{+} \mathrm{T}$ cells, $\mathrm{CD} 3^{+} \mathrm{CD} 8^{+}$ $\mathrm{T}$ cells, CD4/CD8 ratio, $\mathrm{CD} 8^{+} \mathrm{CD} 28^{+} \mathrm{T}$ cells, and Treg cells, whereas an elevated level of $\mathrm{CD}^{+} \mathrm{T}$ cells was observed $(\mathrm{P}=0.035)$ (Fig. 2 and Table III). Remarkably, decreased
Tregs or CD4/CD8 ratio after two cycles of chemotherapy predicts a longer overall survival in patients with unresectable PDAC (Tregs: $\mathrm{P}=0.006$; CD4/CD8 ratio: $\mathrm{P}=0.037$; Fig. 3). Furthermore, circulating Treg levels in stable disease (SD) and partial remission (PR) cases significantly decreased after chemotherapy ( $\mathrm{P}=0.030$; Fig. 4), whereas circulating Treg levels increased in progressive disease $(\mathrm{PD})$ patients $(\mathrm{P}=0.006$; Fig. 4). However, no statistical significance was found in the cohorts concerning CD4/CD8 ratio (Fig. 4). 

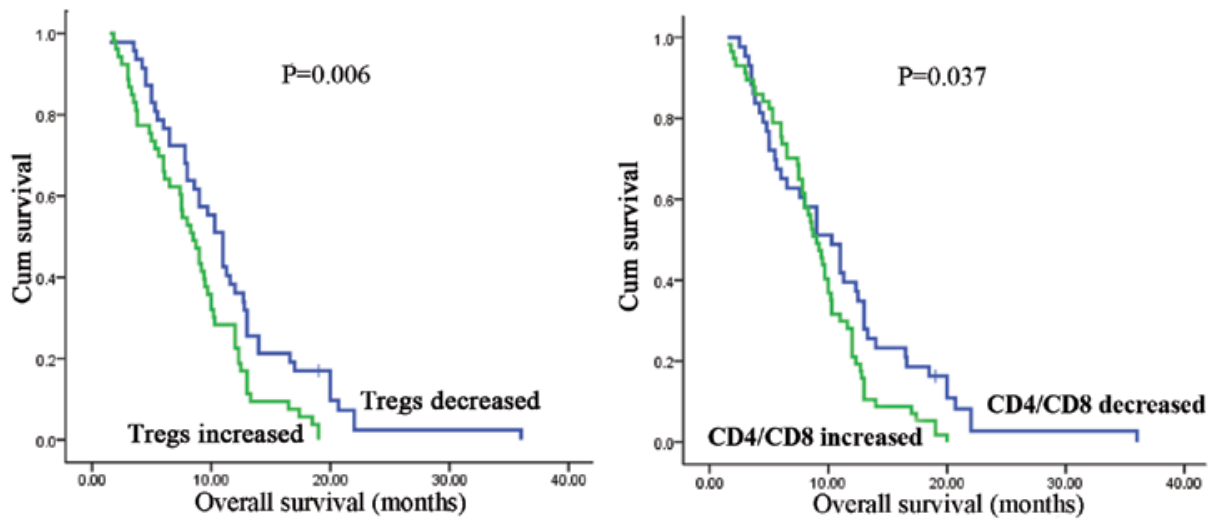

Figure 3. Kaplan-Meier survival curves according to Tregs and CD4/CD8 ratio changes after two cycles of gemcitabine-based chemotherapy.
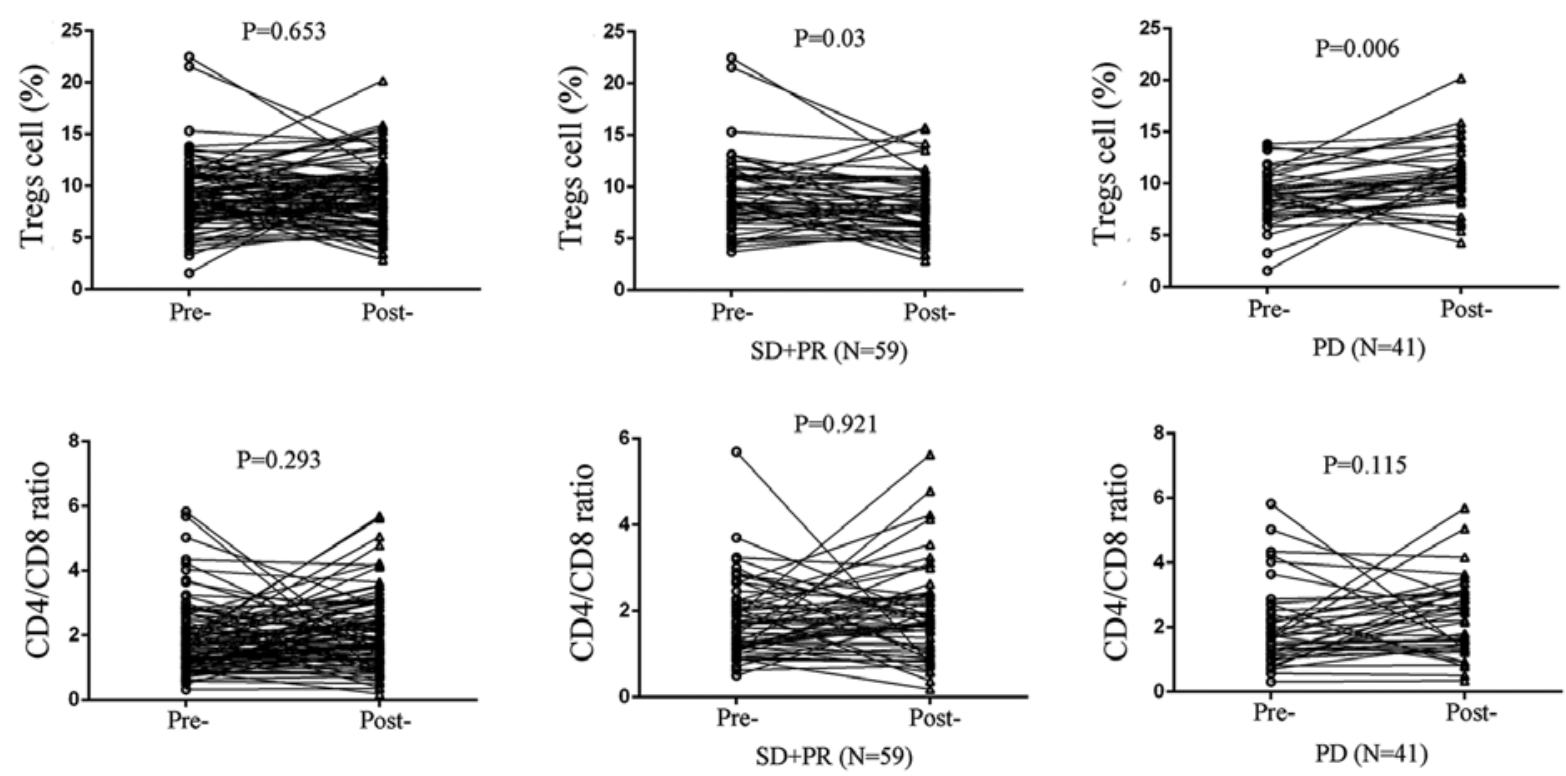

Figure 4. Changes in peripheral CD4/CD8 ratio and Tregs in 100 patients with unresectable pancreatic cancer after two cycles of gemcitabine-based chemotherapy. PR, partial remission; SD, stable disease; PD, progression disease. Pre, pre-chemotherapy; Post, post-chemotherapy.

Table III. Analysis of peripheral T cell subsets in pancreatic cancer patients before or after chemotherapy.

\begin{tabular}{lccr}
\hline & \multicolumn{2}{c}{ Percentages $(\%)($ means $\pm \mathrm{SD})$} & \\
\cline { 2 - 4 } Parameters & Before chemotherapy $(\mathrm{N}=212)$ & After chemotherapy $(\mathrm{N}=100)$ & P-value \\
\hline $\mathrm{CD}^{+}$ & $65.34 \pm 10.84$ & $67.99 \pm 9.06$ & 0.035 \\
$\mathrm{CD}^{+} \mathrm{CD} 4^{+}$ & $38.58 \pm 8.8$ & $39.34 \pm 9.16$ & 0.483 \\
$\mathrm{CD} 3^{+} \mathrm{CD} 8^{+}$ & $22.73 \pm 9.33$ & $23.5 \pm 9.3$ & 0.5 \\
$\mathrm{CD} 4 / \mathrm{CD} 8$ ratio & $1.92 \pm 0.98$ & $2.06 \pm 1.13$ & 0.263 \\
$\mathrm{CD} 8^{+} \mathrm{CD} 28^{+}$ & $9.7 \pm 4.01$ & $10.56 \pm 4.41$ & 0.086 \\
$\mathrm{CD} 4^{+} \mathrm{CD} 25^{+} \mathrm{CD} 127^{-}$ & $8.99 \pm 3.13$ & $9.17 \pm 3.31$ & 0.659 \\
\hline
\end{tabular}

Peripheral IL-17A expression is negatively associated with Tregs in unresectable pancreatic cancer patients treated with chemotherapy. We detected peripheral expression of several cytokines relevant to Treg differentiation, including TGF- $\beta 1$, IL-6 and IL-17A in patients with unresectable PDAC before and after two cycles of chemotherapy, and we found that there was no correlation between Tregs and the expression of either TGF- $\beta 1$ or IL-6 (Fig. 5). However, peripheral IL-17A expression exhibited a negative correlation with Treg level in patients treated with chemotherapy. IL-17A expression was significantly elevated in Tregdecreased patients $(\mathrm{P}=0.001$; Fig. 6), whereas IL-17A level 

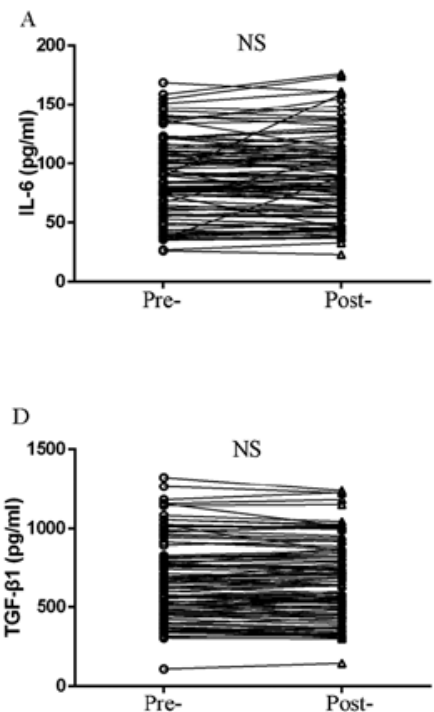
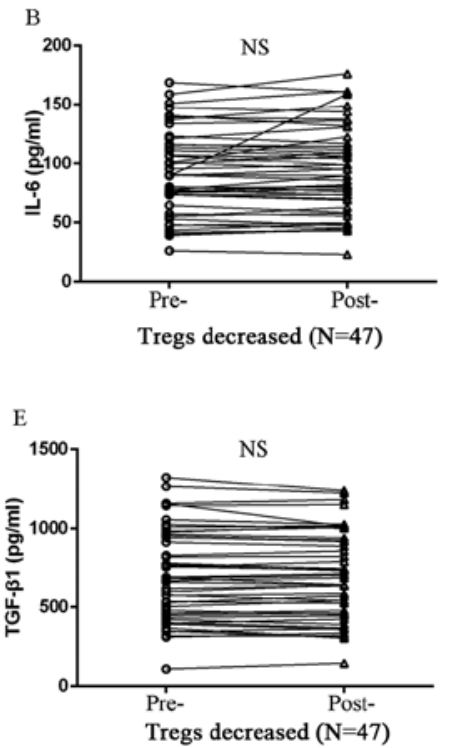
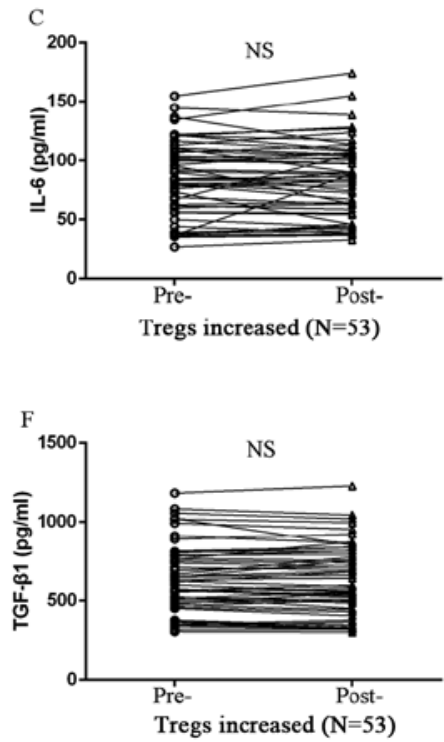

Figure 5. (A and D) Changes in the expression level of IL-6 and TGF- $\beta 1$ in 100 patients with unresectable pancreatic cancer after two cycles of chemotherapy; (B and E) Change in the expression level of IL-6 and TGF- $\beta 1$ in Treg-decreased group (N=47); (C and F) Change in the expression level of IL-6 and TGF- $\beta 1$ in Treg-increased group (N=53). NS, no significance. Pre, pre-chemotherapy; Post, post-chemotherapy.
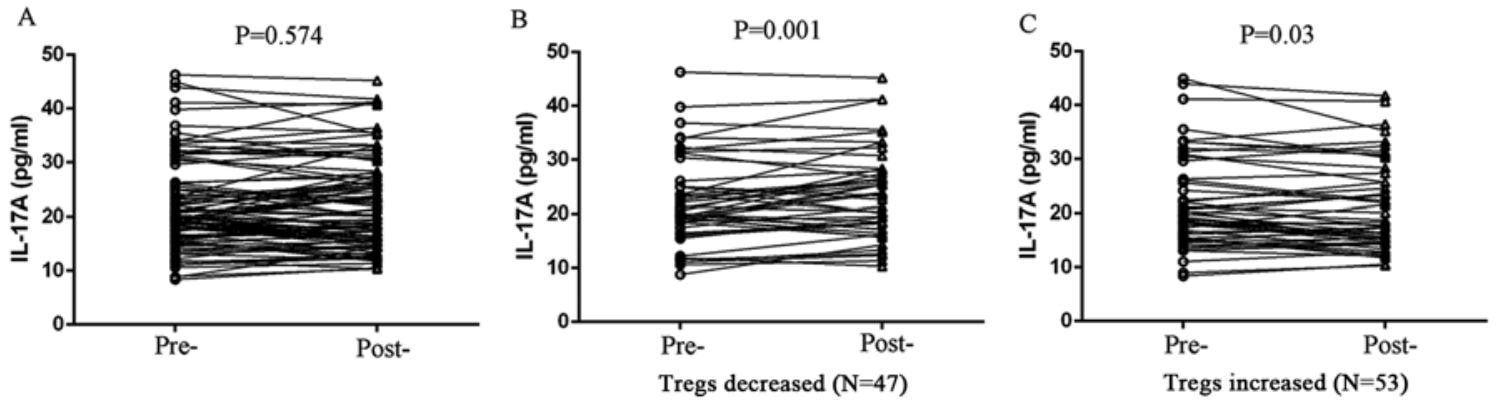

Figure 6. (A) Changes in the expression level of IL-17A in 100 patients with unresectable pancreatic cancer after two cycles of chemotherapy; (B) changes in the expression of IL-17A in the Treg-decreased group ( $N=47)$; (C) changes in the expression of IL-17A in Treg-increased group (N=53). Pre, pre-chemotherapy; Post, post-chemotherapy.

was reduced in Treg-increased patients after chemotherapy ( $\mathrm{P}=0.030$; Fig. 6).

\section{Discussion}

PDAC contains abundant stroma elements surrounding cancer cells, and thereby has a unique biologic profile including chemotherapy resistance and poor prognosis (12). The PDAC specific tumor microenvironment lacks oxygen and blood supply, which contributes to metabolic reprogramming and immune cell adaptation (12-14). Emerging evidence demonstrates that tumor infiltrating $\mathrm{T}$ cells such as Tregs, $\mathrm{CD}^{+} \mathrm{T}$ cells and Th17 cells were associated with prognosis in various human cancers $(15,16)$. In a previous study, we investigated the expression of tumor infiltrating cells within the specimens of resected pancreatic cancer and found that more infiltration of $\mathrm{CD}^{+}$and $\mathrm{CD}^{+} \mathrm{T}$ lymphocytes indicated a better prognosis after surgical resection; in contrast, the primary immunosuppressive factor Tregs and other T helper cell subsets could hardly be detected in PDAC tissues (16). In the present study, the percentage of peripheral
Tregs and CD4/CD8 ratio before treatment was associated with overall survival of patients, exhibiting a circulating T lymphocyte signature in patients with advanced PDAC cases; thus, this may serve as an effective marker for the prognosis of this subgroup of patients before any treatment is done.

Because of the unique tumor microenvironment of PDAC, contributed to by a consistent deprivation of oxygen and nutrients, there will be a persistence of endoplasmic reticulum (ER) stress, which is a mechanism of cell self-protection within the tumor microenvironment of PDAC $(17,18)$. Given that certain chemotherapeutic agents were also stress inducers, there existed a sustained stress status and subsequent tumor metabolism reprogramming in advanced PDAC (19-21). Prolonged ER stress promotes cell apoptosis, but, conversely, might induce cancer cells to acquire more aggressive biologic features to resist chemotherapeutic attack; furthermore, the percentage and types of immune cells recruited by the tumor microenvironment also adapted accordingly (13,14,19-21). In particular, T cell dysfunction owing to nutrient deprivation and tumor metabolism alteration was regarded as a major 
issue of concern in antitumor immune response $(22,23)$. Immune responses to malignant cells can be categorized as locoregional or systemic. In situ, the immune contexture would be essential to accurately define the impact of the local host-immune reaction in tumor (24). It has been well reported that the infiltrating immune cells, in tumor site, play important roles in tumor progression. Unfortunately, in most of the patients with unresectable PDAC, a sufficient amount of tumor tissues to detect intratumoral infiltration of immune cells is difficult to obtain, especially for monitoring chemotherapy-related immune status. Systemic immunity to tumors, as measured in the peripheral circulation, is difficult to demonstrate and tumor-specific responses are particularly elusive. The role of systemic immunity in tumor progression deserves further study. The available evidence suggests that both local and systemic antitumor immunity is compromised in patients with cancer. Many researchers have investigated the correlation of circulating immune cells and tumor infiltrating lymphocytes (TIL) in regard to distribution and function characterization. Circulating $\mathrm{T}$ cells obtained from patients with cancer are either biased in cytokine profile or otherwise functionally compromised. Furthermore, dysfunction in circulating lymphocytes was linked to the extent of dysfunction seen in paired TIL and to the disease stage and/or activity $(25,26)$. It remains controversial whether systemic chemotherapy impairs the immune system. A limited number of patients with pancreatic cancer exhibited a favorable response to systemic chemotherapy, and only limited available options including gemcitabine-based or fluoropyrimidine-based regimens were recommended (9,27). Accordingly, the balance between benefit and risk of chemotherapy in advanced PDAC should be well evaluated. Therefore, if the circulating immune parameters have prognostic value, the markers would be more convenient and accessible to monitor tumor progression. In the present study, the changes in circulating Tregs and $\mathrm{CD} 4^{+} / \mathrm{CD}^{+} \mathrm{T}$ cell ratio before and after chemotherapy discriminate the populations that benefit from chemotherapy, to some extent, and show the divergence in adaption of $\mathrm{T}$ cell immune status responsive to systemic chemotherapy in patients with high PDAC tumor burden. Furthermore, decreased Tregs was detected more in PR and SD cases. Moreover, the increased amount of immunosuppressive $\mathrm{T}$ cells found in PD cases also indicated that PDAC response to chemotherapy was associated with immune adaption of $\mathrm{T}$ cell subsets following a local or systemic stress response or metabolism reprogramming.

The chemotherapeutic agent is a two-edged sword having both immune suppressing and promoting effects. $\mathrm{CD}^{+} \mathrm{T}$ cells contain various $\mathrm{T}$ cell subsets, such as $\mathrm{CD} 4^{+} \mathrm{T}$ cells, $\mathrm{CD} 8^{+} \mathrm{T}$ cells and Tregs. Although our results found that the percentage of $\mathrm{CD}^{+} \mathrm{T}$ cells increased after two cycles of chemotherapy, suggesting chemotherapy does not lead to total $\mathrm{T}$ cell ratio decrease, the change of other $T$ cell subsets need to be further verified. It was shown that some chemo-agents could induce T-cell infiltration into pancreatic cancer. Tsuchikawa et al (28) reported that Foxp3 ${ }^{+} \mathrm{T}$ cell infiltration was significantly lower in the neoadjuvant chemoradiation therapy cases, while the numbers of $\mathrm{CD}^{+}$and $\mathrm{CD}^{+} \mathrm{T}$ cell infiltration had no statistical difference in the tumor microenvironment. Other studies found that $\mathrm{CD}^{+}$and $\mathrm{CD}^{+} \mathrm{T}$ cells were significantly increased after neoadjuvant chemotherapy (29). However, for circulating $\mathrm{T}$ cells, although it was reported that circulating $\mathrm{CD}^{+}$and $\mathrm{CD}^{+} \mathrm{T}$ cells were changed after chemotherapy in other cancers such as breast (30) and cervical cancer patients (31), the relationship between circulating $\mathrm{T}$ cells and chemotherapy was still unclear in pancreatic cancer. In the present study, gemcitabine-based chemotherapy did not exhibit an obviously impaired effect on human $\mathrm{T}$ cell immune system, but underlined some insights that high tumor burden PDAC and continued chemotherapy could result in differentiation of $\mathrm{T}$ cell subsets.

The change of $\mathrm{T}$ cell proportion may be altered by the chemotherapy or by the shrinkage of the tumor. Many studies reported that chemotherapy agents could change tumor microenvironment through various mechanisms, such as increasing lymphocyte infiltration, depletion of Tregs and inducing differentiation of MDSC (32). However, for the circulating lymphocytes, it was still unclear. It was reported that low Treg percentage in circulation at 1 year after pancreatic cancer resection was correlated with improved survival (33). We also previously reported that high Treg percentage in circulation predicts poor prognosis in resectable pancreatic cancer patients (8). We consider that circulating lymphocyte levels are features of immune status in pancreatic cancer patients. Our data showed that Treg cells decreased after chemotherapy in $\mathrm{SD}+\mathrm{PR}$ patients $(\mathrm{N}=59)$, while increased in PD patients $(\mathrm{N}=41)$, suggested that patients with good immune status during the period of chemotherapy, which may be caused by the shrinkage of tumor, are correlated with prognosis. Metabolic features of a hypoxic microenvironment, including glycolysis and Warburg effect, might not only enable cancer cells to develop different biological properties, but may also influence $\mathrm{T}$ cell function and $\mathrm{T}$ cell differentiation (34-36). Several transcription factors and signaling pathways, such as HIF-1 $\alpha$, PD-1 and mTOR signaling are involved in $\mathrm{T}$ cell immune adaptation and differentiation (37). Hypoxia and nutrient deprivation contribute to accumulation of metabolic products and then suppress $\mathrm{CD}^{+} \mathrm{T}$ effector cells and $\mathrm{CD} 4^{+} \mathrm{Th} 1$, Th2 and Th17 subsets, whereas they induce immunosuppressive Treg lineage $(38,39)$. Generally, the percentage of tumor infiltrating $\mathrm{CD}^{+} \mathrm{T}$ cells and $\mathrm{CD}^{+}$effector $\mathrm{T}$ cells indicates a different prognostic value in cancer (40). For $\mathrm{CD}^{+}{ }^{+} \mathrm{T}$ cell subsets, the plasticity between regulatory $\mathrm{T}$ cells and Th17 lineage of $\mathrm{T}$ helper cells has been widely studied recently $(41,42)$. Although Tregs always accompany poor clinical outcomes, Th17 exhibits some inconsistent prognostic significance in various human cancers $(43,44)$. Tregs are reported at elevated frequencies in the peripheral blood and the tumor itself, and correlates with poor outcome. It was reported that Tregs can suppress immune cell activity and induce tumor cell escape from immune surveillance via secreting several cytokines. In addition, it was shown that Tregs complexed with STAT3, a transcription factor that is essential for the differentiation of Th17 cells, then activate IL-17 gene transcription to promote Th17 cell differentiation $(45,46)$. Tregs and Th17 cells are inversely associated in the same tumors, and there is a dynamic interaction between Th17 and Tregs in the tumor microenvironment. The balance of Tregs/Th17 contributed to the shift between pro-inflammatory and anti-inflammatory response and somewhat indicates the prognosis of human cancer $(47,48)$. It was reported that $\mathrm{IL}^{2} 7^{+} \mathrm{FOXP} 3^{+} \mathrm{T}$ cells can be detected in 
tumors, which also express CD25 and TH17 specific marker ROR $\gamma t$ and have suppressive functions. Moreover, Treg cells can transdifferentiate towards an $\mathrm{IL}-17^{+} \mathrm{FOXP} 3^{+} \mathrm{T}$ phenotype and eventually into FOXP3-TH17 cells $(49,50)$. In the study, we detected several cytokines involved with the transdifferentiation between Tregs and $\mathrm{T}$ helper cell subsets in advanced PDAC cases. In addition, we found that the expression of IL-17A, which is characterized by the secretion of Th17, was significantly elevated in the cases whose Treg level was decreased, indicating the possibility that a shift from Tregs to Th17 might be responsible for the sensitivity to chemotherapy in patients with unresectable PDAC.

The present study included locally advanced and metastatic cases of PDAC, the basic characteristics in our group were similar with other studies $(3,51)$. In addition, we also identified an initial CD4/CD8 ratio or Treg level before any treatment was associated with the prognosis via multivariate analyses. Therefore, we concluded the significant difference is valuable. As limitation in the present study, we found that the change of proportion in CD3 positive cells had statistical significance $(\mathrm{P}=0.035)$, while the main subsets of $\mathrm{CD}^{+}$cells such as $\mathrm{CD}^{+}, \mathrm{CD}^{+}$and Treg cells remain stable after chemotherapy. However, we did not detect other T cell subsets (Th1, Th2 or Th17), which might change after chemotherapy. These results need to be further identified via expanding sample sizes and detecting more subsets of immune cells. In addition, we also found that there was no correlation between Tregs and the expression level of either IL-2 or IL-10 (data not shown), while other cytokines such as IFN- $\gamma$ and IL-5, which may be associated with helper T cell subsets or Tregs, were not detected. We will continue to collect samples to validate these results and explore potential mechanisms in future.

Overall, the present study shows a circulating signature of $\mathrm{T}$ cell subsets that could predict the prognosis of patients with unresectable PDAC before treatment. This finding could also predict the response to gemcitabine-based chemotherapy, which could be contributed to by the plasticity of $\mathrm{T}$ cell subsets and their capacity to differentiate from one subset toward another lineage, depending on a high tumor burden PDAC setting or chemotherapy-related metabolic changes.

\section{Acknowledgements}

The present study is supported by grants from the National Natural Science Foundation of China (nos. 81370065, 81372653 and SINO-GERMAN GZ857), and the Basic Research Projects of the Science and Technology Commission of Shanghai Municipality (15JC1401200).

\section{References}

1. Long J, Luo GP, Xiao ZW, Liu ZQ, Guo M, Liu L, Liu C, Xu J, Gao YT, Zheng Y, et al: Cancer statistics: Current diagnosis and treatment of pancreatic cancer in Shanghai, China. Cancer Lett 346: 273-277, 2014.

2. Li D, Xie K, Wolff R and Abbruzzese JL: Pancreatic cancer. Lancet 363: 1049-1057, 2004.

3. Luo G, Guo M, Liu Z, Xiao Z, Jin K, Long J, Liu L, Liu C, Xu J, $\mathrm{Ni} Q$, et al: Blood neutrophil-lymphocyte ratio predicts survival in patients with advanced pancreatic cancer treated with chemotherapy. Ann Surg Oncol 22: 670-676, 2015.
4. Liu C, Lu Y, Luo G, Cheng H, Guo M, Liu Z, Xu J, Long J, Liu L, et al: Which patients with para-aortic lymph node (LN16) metastasis will truly benefit from curative pancreaticoduodenectomy for pancreatic head cancer? Oncotarget 7: 29177-29186, 2016.

5. Wörmann SM, Diakopoulos KN, Lesina M and Algül H: The immune network in pancreatic cancer development and progression. Oncogene 33: 2956-2967, 2014.

6. Curiel TJ, Coukos G, Zou L, Alvarez X, Cheng P, Mottram P, Evdemon-Hogan M, Conejo-Garcia JR, Zhang L, Burow M, et al: Specific recruitment of regulatory $\mathrm{T}$ cells in ovarian carcinoma fosters immune privilege and predicts reduced survival. Nat Med 10: 942-949, 2004.

7. Clark CE, Beatty GL and Vonderheide RH: Immunosurveillance of pancreatic adenocarcinoma: Insights from genetically engineered mouse models of cancer. Cancer Lett 279: 1-7, 2009.

8. Xu YF, Lu Y, Cheng H, Shi S, Xu J, Long J, Liu L, Liu C and $\mathrm{Yu}$ X: Abnormal distribution of peripheral lymphocyte subsets induced by PDAC modulates overall survival. Pancreatology 14: 295-301, 2014.

9. Rébé $\mathrm{C}$ and Ghiringhelli F: Cytotoxic effects of chemotherapy on cancer and immune cells: How can it be modulated to generate novel therapeutic strategies? Future Oncol 11: 2645-2654, 2015.

10. Bardeesy N and DePinho RA: Pancreatic cancer biology and genetics. Nat Rev Cancer 2: 897-909, 2002.

11. Neoptolemos JP, Stocken DD, Friess H, Bassi C, Dunn JA, Hickey H, Beger H, Fernandez-Cruz L, Dervenis C, Lacaine F, et al; European Study Group for Pancreatic Cancer: A randomized trial of chemoradiotherapy and chemotherapy after resection of pancreatic cancer. N Engl J Med 350: 1200-1210, 2004.

12. Luo G, Long J, Zhang B, Liu C, Xu J, Ni Q and Yu X: Stroma and pancreatic ductal adenocarcinoma: An interaction loop. Biochim Biophys Acta 1826: 170-178, 2012.

13. Herbel C, Patsoukis N, Bardhan K, Seth P, Weaver JD and Boussiotis VA: Clinical significance of $\mathrm{T}$ cell metabolic reprogramming in cancer. Clin Transl Med 5: 29, 2016.

14. Molon B, Calì B and Viola A: T cells and cancer: How metabolism shapes immunity. Front Immunol 7: 20, 2016.

15. Yoshida N, Kinugasa T, Miyoshi H, Sato K, Yuge K, Ohchi T, Fujino S, Shiraiwa S, Katagiri M, Akagi Y, et al: A High $\mathrm{ROR} \gamma \mathrm{T} / \mathrm{CD} 3$ ratio is a strong prognostic factor for postoperative survival in advanced colorectal cancer: Analysis of helper T cell lymphocytes (Th1, Th2, Th17 and regulatory T cells). Ann Surg Oncol 23: 919-927, 2016.

16. Wang WQ, Liu L, Xu HX, Wu CT, Xiang JF, Xu J, Liu C, Long J, $\mathrm{Ni} Q \mathrm{X}$ and $\mathrm{Yu} \mathrm{XJ}$ : Infiltrating immune cells and gene mutations in pancreatic ductal adenocarcinoma. Br J Surg 103: 1189-1199, 2016.

17. Antonucci L, Fagman JB, Kim JY, Todoric J, Gukovsky I, Mackey M, Ellisman MH and Karin M: Basal autophagy maintains pancreatic acinar cell homeostasis and protein synthesis and prevents ER stress. Proc Natl Acad Sci USA 112: E6166-E6174, 2015.

18. Li X, Zhu F, Jiang J, Sun C, Zhong Q, Shen M, Wang X, Tian R, Shi C, Xu M, et al: Simultaneous inhibition of the ubiquitinproteasome system and autophagy enhances apoptosis induced by ER stress aggravators in human pancreatic cancer cells. Autophagy 12: 1521-1537, 2016.

19. Kong B, Wu W, Valkovska N, Jäger C, Hong X, Nitsche U, Friess H, Esposito I, Erkan M, Kleeff J, et al: A common genetic variation of melanoma inhibitory activity-2 labels a subtype of pancreatic adenocarcinoma with high endoplasmic reticulum stress levels. Sci Rep 5: 8109, 2015.

20. Mahalingam D, Patel S, Nuovo G, Gill G, Selvaggi G, Coffey M and Nawrocki ST: The combination of intravenous Reolysin and gemcitabine induces reovirus replication and endoplasmic reticular stress in a patient with KRAS-activated pancreatic cancer. BMC Cancer 15: 513, 2015.

21. Cheng S, Swanson K, Eliaz I, McClintick JN, Sandusky GE and Sliva D: Pachymic acid inhibits growth and induces apoptosis of pancreatic cancer in vitro and in vivo by targeting ER stress. PLoS One 10: e0122270, 2015.

22. Ho PC, Bihuniak JD, Macintyre AN, Staron M, Liu X, Amezquita R, Tsui YC, Cui G, Micevic G, et al: Phosphoenolpyruvate is a metaboliccheckpoint of anti-tumor $\mathrm{T}$ cell responses. Cell 162: 1217-1228, 2015. 
23. Biswas SK: Metabolic reprogramming of immune cells in cancer progression. Immunity 43: 435-449, 2015.

24. Fridman WH, Pagès F, Sautès-Fridman $\mathrm{C}$ and Galon J: The immune contexture in human tumours: Impact on clinical outcome. Nat Rev Cancer 12: 298-306, 2012.

25. Reichert TE, Strauss L, Wagner EM, Gooding W and Whiteside TL: Signaling abnormalities, apoptosis, and reduced proliferation of circulating and tumor-infiltrating lymphocytes in patients with oral carcinoma. Clin Cancer Res 8: 3137-3145, 2002.

26. Fu J, Zhang Z, Zhou L, Qi Z, Xing S, Lv J, Shi J, Fu B, Liu Z, Zhang JY, et al: Impairment of $\mathrm{CD}^{+}$cytotoxic $\mathrm{T}$ cells predicts poor survival and high recurrence rates in patients with hepatocellular carcinoma. Hepatology 58: 139-149, 2013.

27. Ryan DP, Hong TS and Bardeesy N: Pancreatic adenocarcinoma. N Engl J Med 371: 1039-1049, 2014.

28. Tsuchikawa T, Hirano S, Tanaka E, Matsumoto J, Kato K, Nakamura T, Ebihara Y and Shichinohe T: Novel aspects of preoperative chemoradiation therapy improving anti-tumor immunity in pancreatic cancer. Cancer Sci 104: 531-535, 2013.

29. Homma Y, Taniguchi K, Murakami T, Nakagawa K, Nakazawa M Matsuyama R, Mori R, Takeda K, Ueda M, Ichikawa Y, et al: Immunological impact of neoadjuvant chemoradiotherapy in patients with borderline resectable pancreatic ductal adenocarcinoma. Ann Surg Oncol 21: 670-676, 2014.

30. Bailur JK, Pawelec G, Hatse S, Brouwers B, Smeets A, Neven P, Laenen A, Wildiers H and Shipp C: Immune profiles of elderly breast cancer patients are altered by chemotherapy and relate to clinical frailty. Breast Cancer Res 19: 20, 2017.

31. van Meir H, Nout RA, Welters MJ, Loof NM, de Kam ML, van Ham JJ, Samuels S, Kenter GG, Cohen AF, Melief CJ, et al: Impact of (chemo)radiotherapy on immune cell composition and function in cervical cancer patients. OncoImmunology 6: e1267095, 2016

32. Tsuchikawa T, Takeuchi S, Nakamura T, Shichinohe T and Hirano S: Clinical impact of chemotherapy to improve tumor microenvironment of pancreatic cancer. World J Gastrointest Oncol 8: 786-792, 2016.

33. Yamamoto T, Yanagimoto $\mathrm{H}$, Satoi $\mathrm{S}$, Toyokawa $\mathrm{H}$, Hirooka $\mathrm{S}$, Yamaki S, Yui R, Yamao J, Kim S and Kwon AH: Circulating $\mathrm{CD} 4{ }^{+} \mathrm{CD} 25^{+}$regulatory $\mathrm{T}$ cells in patients with pancreatic cancer. Pancreas 41: 409-415, 2012.

34. Cairns RA, Harris IS and Mak TW: Regulation of cancer cell metabolism. Nat Rev Cancer 11: 85-95, 2011.

35. Pavlova NN and Thompson CB: The emerging hallmarks of cancer metabolism. Cell Metab 23: 27-47, 2016.

36. DeBerardinis RJ, Lum JJ, Hatzivassiliou G and Thompson CB: The biology of cancer: Metabolic reprogramming fuels cell growth and proliferation. Cell Metab 7: 11-20, 2008.

37. Speiser DE, Ho PC and Verdeil G: Regulatory circuits of T cell function in cancer. Nat Rev Immunol 16: 599-611, 2016.
38. Dang EV, Barbi J, Yang HY, Jinasena D, Yu H, Zheng Y, Bordman Z, Fu J, Kim Y, et al: Control of $\mathrm{T}_{\mathrm{H}} 17 / \mathrm{T}_{\text {reg }}$ balance by hypoxia-inducible factor 1. Cell 146: 772-784, 2011.

39. Sinclair LV, Rolf J, Emslie E, Shi YB, Taylor PM and Cantrell DA: Control of amino-acid transport by antigen receptors coordinates the metabolic reprogramming essential for $\mathrm{T}$ cell differentiation. Nat Immunol 14: 500-508, 2013.

40. Huang Y, Ma C, Zhang Q, Ye J, Wang F, Zhang Y, Hunborg P, Varvares MA, Hoft DF, Hsueh EC, et al: $\mathrm{CD}^{+}$and $\mathrm{CD}^{+} \mathrm{T}$ cells have opposing roles in breast cancer progression and outcome. Oncotarget 6: 17462-17478, 2015.

41. Guéry L and Hugues S: Th17 Cell plasticity and functions in cancer immunity. BioMed Res Int 2015: 314620, 2015.

42. Ivanova EA and Orekhov AN: T Helper lymphocyte subsets and plasticity in autoimmunity and cancer: An overview. BioMed Res Int 2015: 327470, 2015 .

43. Chaudhary B, Elkord E and Regulatory T: Regulatory T cells in the tumor microenvironment and cancer progression: Role and Therapeutic Targeting. Vaccines (Basel) 4: E28, 2016.

44. Alizadeh D, Katsanis E and Larmonier N: The multifaceted role of Th17 lymphocytes and their associated cytokines in cancer. Clin Dev Immunol 2013: 957878, 2013.

45. Chaudhry A, Rudra D, Treuting P, Samstein RM, Liang Y, Kas A and Rudensky AY: CD4+ regulatory T cells control TH17 responses in a Stat3-dependent manner. Science 326: 986-991, 2009.

46. Wang X, Wang L, Mo Q, Dong Y, Wang G and Ji A: Changes of Th17/Treg cell and related cytokines in pancreatic cancer patients. Int J Clin Exp Pathol 8: 5702-5708, 2015.

47. Gagliani N, Amezcua Vesely MC, Iseppon A, Brockmann L, $\mathrm{Xu} \mathrm{H}$, Palm NW, de Zoete MR, Licona-Limón P, Paiva RS, Ching T, et al: Th17 cells transdifferentiate into regulatory T cells during resolution of inflammation. Nature 523: 221-225, 2015.

48. Yang G, Li H, Yao Y, Xu F, Bao Z and Zhou J: Treg/Th17 imbalance in malignant pleural effusion partially predicts poor prognosis. Oncol Rep 33: 478-484, 2015.

49. Chellappa S, Hugenschmidt H, Hagness M, Line PD, Labori KJ, Wiedswang G, Taskén K and Aandahl EM: Regulatory T cells that co-express ROR $\gamma$ t and FOXP3 are pro-inflammatory and immunosuppressive and expand in human pancreatic cancer. OncoImmunology 5: e1102828, 2015.

50. Zou W and Restifo NP: $\mathrm{T}_{\mathrm{H}} 17$ cells in tumour immunity and immunotherapy. Nat Rev Immunol 10: 248-256, 2010.

51. Von Hoff DD, Ervin T, Arena FP, Chiorean EG, Infante J, Moore M, Seay T, Tjulandin SA, Ma WW, Saleh MN, et al: Increased survival in pancreatic cancer with nab-paclitaxel plus gemcitabine. N Engl J Med 369: 1691-1703, 2013. 